\title{
Understanding the Relationships between Fields of Research
}

\author{
Andrew Basden \\ Emeritus Professor of Human Factors and Philosophy in Information Systems, University of \\ Salford, UK \\ basdentab@gmail.com
}

\begin{abstract}
This paper suggests how mutual understanding and respect may be fostered between very different fields of research, which seem to have little in common. The meaning and value of each field, and the relationships among them, are revealed using Dooyeweerd's aspects. Dooyeweerd is rare among philosophers in having made an intensive study of the diversity and coherence of meaningfulness. In this way, researchers in one field can more fully understand the ways in which findings or research in other fields are meaningful. Dooyeweerd's inter-aspect relationships help us understand the types of relationship a field might have with others.
\end{abstract}

Keywords: Inter-field relationships; Interdisciplinary research; Integration of research fields; Aspects; Dooyeweerd's philosophy

\section{Introduction}

In a provocative article, Carr [2003] argues that "IT doesn't matter" - that information technology (IT) is of little consequence to business. In its early days (1970s - 1980s) IT provided competitive advantage to some firms who used it more adroitly than others (as a "proprietary technology"), but as IT became an "infrastructure technology" and all firms used IT, no further competitive advantage was possible. Carr sees parallels with railway, electricity and telegraph technologies, which at first gave competititve advantage but became mere infrastructure on which all firms depended. He predicted that IT is no longer a matter for company strategists.

Such seeming arrogance and disrespect provokes unhelpful responses; the information systems community, abuzz with indignation, responding with defensive reaction. Both arrogance and reaction sap goodwill and hinder inter-field communication, to the detriment of research and practice as a whole. In addition, Carr turned out to be wrong, in that branches of IT like social media became highly strategic to businesses.

Mutual respect is needed for interdisciplinary research and practice. Boden (1990) argued that there are grades of interdisciplinarity, culminating in "integrated interdisciplinarity" in which each participant has good understanding of what is meaningful in the other fields (Strijbos \& Basden 2006). Most interdisciplinary research falls short of this. Interdisciplinary working requires knowledge of, and respect for, the methods and perspectives of other fields, and especially the intellectual contribution of colleagues from other disciplines [Urbanska et al. 2019]. In this paper we focus on perspectives and contribution, and intend to discuss methods later.

Respecting the perspective and intellectual contribution of a field requires understanding how they are meaningful. What is meaningful to one field might, at first sight, be meaningless to others; for example physicists and sociologists rarely find each others' findings meaningful in their own research. How can Carr find IT meaningful, when his entire argument is that it is not? To engender respect, we need a foundation for understanding ways in which reality can be meaningful and how they relate to each other.

This is the role of philosophy, "The Discipline of Disciplines" [Strauss 2009]. Unfortunately, most philosophies tend to be serviceable in only a limited range of fields - for instance Habermas and Luhmann in the social sciences, Marx in the societal, Heidegger in psychological and design, Aristotle and Liebniz in the natural sciences, etc., as Strauss [2009] shows. Few can truly do justice to what is meaningful across all fields. Dooyeweerd's [1955] philosophy, however, can do so, because it concerns itself with meaningfulness.

This is not a philosophical paper but rather it applies philosophy. It does not follow the normal structure of a scientific paper (literature review, research methods, research results, discussion) but rather presents a paradigm in the Kuhn's [1962] sense of "way of seeing things" [Masterman 1970]. 
So section 2 outlines what is needed of Dooyeweerd's philosophy for this discussion. Section 3 sets out what is meaningful in each kind of field, section 4 discusses implications for research that might apply across all fields, and section 5 concludes.

\section{Dooyeweerd's Philosophy of Meaningfulness}

Dooyeweerd's concern with meaningfulness was not only philosophical (meaning as the root of being and the presupposition of all philosophy) but also practical, in that he took more seriously than most the diversity of meaning we experience in everyday activity and in the pre-theoretical attitude of thought (intuition). Many philosophies try to reduce this diversity to one or two aspects, which leads to impoverished explanations and misleading diagnoses and remedies, and also to the kind of arrogance depicted above, as we shall see.

Instead, Dooyeweerd held to a non-reductionist approach [Clouser 2005]. His philosophy has been applied across the entire range of fields - mathematics and the natural, psychological, design, social and societal sciences [Basden 2020, Chapter 11]. What enabled him to take this approach might have been his radically different background emerging from Dutch Christian thinking [Basden 2020, Chapter 5].

\subsection{Diversity of Meaningfulness}

Dooyeweerd did not allow meaning to fragment but set out to understand in which ways things can be meaningful, and their associated kinds of fundamental law by which things occur and operate. From a penetrating study of what thinkers had written about them over the last 2500 years since the Greek philosophers, right up to the 20th century, Dooyeweerd [1955, II, 1-426] delineated fifteen fundamentally distinct aspects (ways of being meaningful) of reality as a whole.

Dooyeweerd believed $[1955,1,3]$ that reality has a numeric aspect that we can study using arithmetic, statistics and its laws are those of algebra; a spatial and a kinematic aspect, whose laws are those of geometry, topology and mechanics; a physical aspect; a biotic aspect where we study life functions; a psychical or sensitive aspect, with its laws of psychology in its behaviourist forms; an analytic aspact in which conceptualization and logic are meaningful, a formative aspect to do with human deliberate forming of things in reality whether it is clay into a pot, ideas into an plot or model, or people into a social group, and which makes things like techniques, tools and technologies meaningful. There is a lingual aspect of reality to do with expression and signification; a social aspect to do with working together as a group or in relationships, in agreement; an economic aspect to do with frugal management of limited resources; an aesthetic aspect, to do with harmony and joy, delight and fun, humour and leisure; a juridical aspect to do with justice and due, whether formal justice as in the State and its laws and policies, or an informal justice as in appropriateness and proportionality, an ethical aspect of self-giving love that goes beyond what is due and governs attitudes in both individuals and across society, as pervading attitudes; and a pistic aspect (from the Greek pistis) of commitment, faith, vision, referring to what is ultimately meaningful and valuable.

Dooyeweerd's list of aspects is not intended as any final truth but rather as a provisional 'best guess', always open to expansion and modification as our understanding of reality progresses [Dooyeweerd 1955,II,556]. Some systems thinkers have also addressed the question of which aspects there are, usually as system levels [Bunge 1979], systems genera [Hartmann 1952], types of need [Maslow 1943], etc. Readers may employ those if they prefer, but Dooyeweerd's suite has advantages, in being more comprehensive and integrating classification with normativity [Basden 2020].

Dooyeweerd's suite of aspects is also more deeply grounded in philosophy in that aspects are not just properties but are irreducibly distinct spheres of meaningfulness and law, centred on a "meaning kernel", which underlie all being, functioning, normativity, possibility and time. The kernel of each is approximately expressed in its name and outlined in Section 3.

Each aspect defines a basic kind of law-like potential in which things can function, in a way that contributes to the good of the whole. Quantitative to physical laws are largely determinative while those of the biotic to pistic are increasingly non-determinative. THey also define a dysfunction or harm corresponding to the good (examples: disease v. health (biotic), confusion v. clarity (analytical), injustice v. justice (juridical)). Thus Dooyeweerd's aspects can be used to discuss kinds of quality and to guide practice, and ensure that normative issues are always considered during research. 
So here we adopt Dooyeweerd's suite - though always provisionally.

\subsection{Fields}

Dooyeweerd developed a philosophy of science in which each broad scientific area focuses on a core aspect (or maybe several if interdisciplinary), for example the physical sciences on the physical aspect, the social sciences on the social, and theology on the pistic [c.f. Winch 1958]. This can explain why those working in one field (discipline or science) take little interest in the issues meaningful in different fields. Table 1 shows typical fields that focus on each aspect, and examples of some research questions meaningful therein.

Table 1: Dooyeweerd's suite of aspects and fields that focus on each

\begin{tabular}{|c|c|c|}
\hline Aspect & Typical Field & Example Main Research Question \\
\hline Quantitative & $\begin{array}{l}\text { Arithmetic, } \\
\text { Statistics }\end{array}$ & Is every even integer the sum of two primes (Goldbach Conjecture)? \\
\hline Spatial & Geometry & $\begin{array}{l}\text { Can an n-dimensional convex body admit an expansive homeomorphism? [Klee } \\
\text { 1960] }\end{array}$ \\
\hline Kinematic & Mechanics & How can we get linear motion from rotary motion? \\
\hline Physical & Physics & What is the electric charge radius of the proton? \\
\hline Organic-Biotic & Life sciences & How do cells determine what size to grow before dividing? \\
\hline $\begin{array}{l}\text { Psychical- } \\
\text { Sensitive }\end{array}$ & Psychology & How does previous experience alter perception and behaviour? \\
\hline Analytic & Analysis, Logic & What are the limits of understanding thinking as a form of computing? \\
\hline Formative & Design sciences & How to optimally cut a cake so that every recipient feels they have a fair piece? \\
\hline Lingual & Linguistics & How does grammaticalization function? \\
\hline Social & Sociology & Does social media make us lonely? \\
\hline Economic & Finance & $\begin{array}{l}\text { Why is it that individuals or institutions in many countries hold only modest } \\
\text { amounts of foreign equity? }\end{array}$ \\
\hline Aesthetic & Aesthetics & What is the line between art and non-art? \\
\hline Juridical & Jurisprudence & How may we compare Indian and Iranian laws? \\
\hline Ethical & Ethical theory & Why do many people pursue hedonistic lifestyles? \\
\hline Pistic & Theology & $\begin{array}{l}\text { What is the relationship between belief, commitment, courage and motivation in } \\
\text { each religion? }\end{array}$ \\
\hline
\end{tabular}

\subsection{Inter-aspect and Inter-field Relationships}

The core aspect distinguishes fields but how do they relate to each other? Though aspects are irreducibly distinct in their kernel meanings, they relate to each other in several ways, forming a "coherence of meaning" [NC,II, 4]. These inter-aspect relationships are inherent in aspects, not a social construction. Understanding them can assist (especially interdisciplinary) research. Dooyeweerd, unfortunately, did not clearly separate out different kinds of inter-aspect relationship that occur. He discussed them all together but Basden [2020, 52-55] has usefully attempted to distinguish the following, which is a summary with some implications for research added.

1. Simultaneity. The situations we research function in all aspects simultaneously. Research focuses on core aspect(s) for study, abstracting it from the situation [Clouser 2005; NC,I, 38-44]. Yet functioning in our core aspect(s) is affected by that in others in the following ways, so they need to be taken into account even while we focus.

2. No conflict. No aspect inherently contradicts or undermines the norms or functioning of others. So we should not expect conflicts. When conflicts appear, for example the belief that being ethical in business jeopardises business success, the researcher should question whether the meaningfulness or laws of an aspect has been misunderstood (e.g. economic aspect misunderstood as short-term profits) and then refresh their perspective and even paradigm.

3. Targeting. Functioning in one aspect 'targets' others. For example, when we say "An atom ..." or "An aspiration ...", we function in the lingual aspect and target the physical and pistic aspects respectively. Since our core aspect might function differently when targeting different aspects this can deepen our understanding. It might require different research methods. 
4. Inter-aspect analogy. Each aspect contains echoes of what is meaningful in all the others. For example, causality is physical but is echoed in logical implication and historical bringing-about [Geertsema 2002]. Recognising such analogies can stimulate fresh ideas (for example the lingual analogy of information in quantum physics) and can then bring clarity, in that analogies of aspect $X$ in aspect $Y$ are governed by laws of $Y$, not $X$. Analogies should not be expected to be governed by the laws of their origin aspect.

5. Order of aspects. The aspects form a sequence of earlier to later (not lower to higher because, Dooyeweerd contended, all are equally important). Each is like a sphere of meaningfulness, which antecipates ("ante" = before [Strauss 2009]) or retrocipates others, as shown in Figure 1. The history of science/research shows something of the aspectual sequence, with the mathematical aspects being explored by the ancient Greeks, the natural sciences several centuries ago and then the social sciences. This order is important in interaspect dependency.

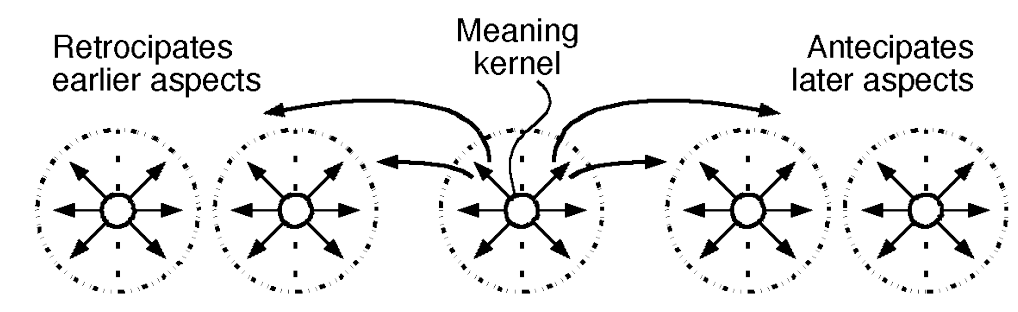

Figure 1: Aspects (spheres of meaning) in sequence

Copyright (c) The Dooyeweerd Pages 2021, used with permission.

6. Inter-aspect dependency. Each aspect depends on other aspects, but differently for earlier and later. Foundational dependency (or retrocipatory dependency) means that functioning in an aspect depends on good functioning in an earlier aspect (e.g. as social does on lingual). The earlier aspects provide a substratum or foundation, as in Hartmann's notion of lower strata 'bearing' higher ones. Research into a core aspect soon takes account of the findings of research into earlier aspects.

Transcendental dependency (or antecipatory dependency [NC,III, 108]) works in the opposite direction, an earlier aspect depends on a later for the full opening up of its meaningfulness and potential. For example, our lingual functioning would be extremely limited if never employed in social activity. Taking account of the meaningfulness of later aspects widens out that of the core aspect. For example, irrational numbers are quantitative but antecipate (only make sense in the light of) spatial meaningfulness. Polanyi \& Prosch [1975, 178] puts this well,

"Just as arithmetic is not logically rich enough for us to deduce a calculus from it, and words are not rich enough for us to deduce a grammar from them, so the laws of physics and chemistry would now be understood to be not rich enough for us to deduce the characteristics of sentience from them, and we should cease trying to do so."

Given these inter-aspect relationships, no aspect can be reduced to others. (a) No aspect is self-dependent, on which all others depend [Clouser 2005]. (b) No aspect can be derived from others, even in combination. (c) Each aspect is equally important. Reductionism, which Dooyeweerd [NC,II, 335] characterizes as "deification of the temporal meaning-aspects," violates these and severs the relationships. As will be discussed later, it can engender arrogance and conflict and close down cross-fertilization of ideas. Reductions can seem to work for a time because of inter-aspect analogies [NC,II, 331-3], and can be useful in the early days of a field, but they ultimately do a disservice to both theory and practice.

A pattern emerges. At the birth of a field, researchers study what is meaningful in its core aspect, then they begin taking account of what is meaningful in earlier neighbouring aspects, and this brings the field to some kind of young maturity. This builds theoretical knowledge of what Dooyeweerd called the "closed structure" or "retrocipatory structure" of the aspect. To reach full maturity, what is meaningful in later aspects is taken into account, building knowledge of Its open, or antecipatory, structure. Both are illustrated for the lingual aspect below, and the latter for the quantitative aspect. Good researchers take all aspects into account, often intuitively, and understand the role each plays in their field. 
It is often applications that stimulate this, because in 'real life' the functioning of each aspect is influenced by the others. Applied research is especially useful in supplying diverse targets, and forcing us to take antecipations into account. It is important, not only to businesses etc., but to pure research itself.

Section 3 goes through the aspects in turn to briefly discuss them, so that we can understand the potential relationships among fields.

\section{Aspects and their fields}

This section discusses the meaningfulness of each aspect and how it relates to others. Each aspect introduces something meaningful that cannot be understood in earlier aspects, but which depends on them and on later aspects for full understanding of its meaningfulness. Each section begins by introducing its kernel (by means of a collection of terms, because no one term can properly express it) and its relevance to business. Then Dooyeweerd's discussion of the aspect in his General Theory of Modal Spheres [NC,II, 1-426] is heavily summarised, so readers may delve deeper, but, since his coverage is variable, it is augmented with other material, especially for the lingual aspect. At the end, this discussion is applied to fields from all areas.

\subsection{The Quantitative, Spatial and Kinematic Aspects}

The mathematical aspects, quantitative, spatial and kinematic, are pre-physical, needing no physical manifestation.

The quantitative aspect concerns discrete amount, about which more and less are meaningful, and hence linear sequence. Its rationality and functioning include the arithmetic operations. Research in this aspect can be about fractions, prime numbers, probabilities, infinity and so on. What the amount is of (words, concepts, pebbles, sand, sides of a shape, etc.) is of little concern to the quantitative aspect itself, being only targets of its functioning - though some kinds of targets might nuance that functioning.

The spatial aspect concerns extendedness, about which shape, location and relationships like proximity and inside-outside are meaningful. Its rationality is geometric and topological (trigonometry transduces spatial to quantitative). There is a continuousness and simultaneity about spatial reality that is meaningless to the quantitative aspect. Spatial functioning depends on quantitative in number of dimensions and, for example, in number of sides of a shape.

The kinematic aspect concerns movement, making concepts like route, divergence and rotation meaningful. Movement depends on the spatial aspect and may be quantified as speed, but the kinematic aspect cannot be reduced to either.

These three aspects relevant to business as, for example, transport, location and accounting, and the quantitative aspect is also much used in statistical research methods. Though often treated as conceptual, Dooyeweerd believes that mathematical things like quantities, locations and movement 'exist' without conceptualisation or physicality, which they antecipate.

Dooyeweerd [1955,II, 79-106] discusses in some depth what the kernel meanings of these three aspects are, charting some of the history of mathematical thought. The original, basic meaningfulness offered by the quantitative aspect is that of 'how much' with the cardinal numbers in sequence, with fractions in between derived from them. Irrational numbers anticipate the spatial aspect, and differential calculus, the kinematic aspect. From the quantitative aspect alone, these can never be reached but only approximated. Dooyeweerd rejects the claim of some intuitionist mathematicians that they are mere human constructions, arguing instead that they are inherent in the anticipatory structure of the aspects (p.88). In similar vein he discusses imaginary numbers (p.93;104), infinity (p.87), infinitesimals (p.87), Cantors transfinite numbers (p.80-88), and so on.

Until we understand clearly the kernels of each aspect in their irreducible meaningfulness and inter-aspect relationships, researchers in mathematics will find trouble, especially when we presume that mathematics is based on logic. For example, when we try to reduce movement to a sequence of spatial points, we hit Zeno's paradox (Achilles-tortoise race). As Dooyeweerd poetically remarked, "The cosmic order takes revenge on the rationalistic trend of thought in mathematics which in theory eradicates the modal boundaries of meaning 
between number, space, movement" (p.93). Because they were intuitively aware of this irreducibility, the Pythagoreans resisted the idea of irrational numbers, and Leibniz resisted negative numbers.

Dooyeweerd clarified that counting is not a quantitative function but an analytical one with a strong quantitative component, and that mathematical statements are not truths but lingual significations of what we believe about quantitative laws.

\subsection{The Physical Aspect}

The physical aspect concerns energy/mass, forces, causality and irreversibility, which are subject to laws of electromagnetism, gravity, thermodynamics, relativity, quantum mechanics, etc. Except at the microscopic level, physical laws are determinative and predictable. It is relevant in business as, for example, electric power, pollution and climate change emissions.

All these depend retrocipatively on the kinematic, spatial and quantitative aspects, so it is no surprise that mathematics pervades physics, chemistry, etc. Yet they cannot be reduced to mathematics, which knows nothing innately about forces or causality (except by analogy or targeting); for example fluid dynamics requires not just kinematics but forces and causality. Analogies of forces and causality are found in most fields, and recognising Dooyeweerd's distinction between original and analogical meaning helps us clarify concepts. Physical space that is bent by matter (General Theory of Relativity), and might even be discrete rather than continuous, is only an analogy, not original space [NC,II, 101], following physical not spatial laws. Chemistry, especially in biochemistry, antecipates plant biology and geology antecipates ecology. Quantum information might antecipate the lingual.

\subsection{The Organic or Biotic Aspect}

The organic-biotic aspect concerns life - cells, organs, bodies, organisms, ecologies, progeny and species, with functions like feeding, health, injury, growth, death, reproduction, self-maintenance, etc., which plants, animals and humans, but not rocks, exhibit. It is relevant in business as, for example, health, pandemics, etc"

In discussing why he chose life as the kernel, Dooyeweerd [NC,II, 107-111] prefigures later debates over whether procreation or self-maintenance define life, and could lend clarity concepts like autopoiesis [Maturana \& Varela 1980]. Biotic functioning depends on physical, in bodily structures, in chemical processing. Analogies of growth and health occur throughout most fields.

\subsection{The Psychical or Sensitive Aspect}

The psychical aspect concerns sensorimotor stimulus and response, memory, recognition and animal feelings like hunger and fear - which are relevant to business in many ways. (Human feelings target later aspects e.g. wonder, the pistic). Functions like affordance [Gibson 1979] are psychical but target biotic and physical aspects.

Dooyeweerd [p.111-8] discusses why he expressed this aspect as feeling, rather than for example soul (psyche) or Erlebnisse, and then how it depends on biotic, physical and kinematic aspects. He discusses only organisms and not psychical functioning of neurones and their interaction.

Psychical recognition, such as of mates, antecipates analytical distinction, but obeys psychical not analytical laws. This offers a philosophical ground for distinguishing memory from concepts, and thus behaviourist from cognitive psychology.

\subsection{The Analytic Aspect}

The analytic aspect concerns distinction-making, in conceptualising, attention-giving, logic, etc. which, of course, are important in business. Dooyeweerd [NC,II, 118-125] mainly discusses logic, whose key law and rationality concerns "identity, contradiction and sufficient ground" [c.f. Clouser 2005]. Contradiction is analytical dysfunction. (Category errors, however, are not contradictions, but reductions of one aspect to another.) Analogies of identity are encountered in most fields.

Analytical functioning depends on psychical (mental) processing but cannot be reduced to it; neural studies have shown individual concepts do not map to individual neurones. Dooyeweerd discusses antecipations like logical form (formative), logical symbolism (lingual), and Occam's razor (economic) [p.121-4]. 


\subsection{The Formative Aspect}

The formative aspect concerns formative power as exhibited in human deliberate action and achievement, in history, construction, innovation, control (power-over), means and ends, planning, structures, techniques, tools, industry, technologies, etc. Its dysfunctions include laziness or wanton destruction. All these are crucial to business in many ways. Dooyeweerd called it the cultural or historical aspect, but in English these have different connotations. Formative power targets various aspects, with different things being formed, such as materials (physical), spatial arrangements, ideas (analytical), intentions (formative), data (lingual), institutions (social), etc.

Dooyeweerd extensively discusses this aspect in its manifestation as history and the problems of philosophical historicism [Dooyeweerd 1955,II,190-298], but most is irrelevant to us. He traces retrocipations in analytical identity (as in historical events) [p.229-32], psychical volition [p.244] and biotic genetics. Dooyeweerd discusses antecipations in the guise of historical development in fields centred on later aspects.

\subsection{The Lingual Aspect and its Discourses}

The lingual aspect's kernel is "symbolic signification", expressing meanings in symbols/signs, which may be subsequently interpreted - information carried by objects like words and sentences, boundary stones, texts, stories, languages, etc., which are generated by writing, speech, gestures, etc. It is important for business records, information and communications, including advertising.

Whereas the individual's meanings in psychical to formative functioning are fleeting and largely internal, lingual functioning externalises distinct meanings in some medium, so they are accessible to others and/or can be picked up later. Lingual laws include not only those of phonetics, vocabulary, grammar (syntax), in which we see dependence on psychical, analytical and formative aspects, but also those of semantics, and even those of pragmatics (the reason why an utterance occurs). Lingual functioning depends antecipatorily on social agreement over the meaning of words and phrases and on aesthetic allusion in idioms and jokes.

Dooyeweerd's discussion of the lingual aspect is sparse [NC,II, 221-7,284-5]. So we discuss it differently and more fully, by interpreting some of the main discourses of the field from an aspectual perspective. Some post-date Dooyeweerd.

The disciplines of literature and linguistics studied the lingual aspect, often with other aspects incorporated intuitively. Explicit consideration of lingual dependencies on earlier aspects may be found in the mathematician, Frege, asking how it is possible for (logical-mathematical) symbols to stand for (signify) anything, Morris and Skinner, treating language as stimulus and response of individuals (psychical aspect), and Chomsky, treating language as a (supervening) property of mental states that develops in the individual as internal "I-language" (psychical, analytical aspects). Piaget was interested in cognitive structures (analytical-psychical aspect) with a biotic foundation in child development.

Peirce is one thinker who closely explored the lingual aspect as such, with his triad of sign, signifier and signified. Being of the Pragmatist tradition, he also explored a link with the formative aspect, as did Austin, Searle and Wittgenstein. They were interested in what language achieves in everyday life in speech acts and language games. Gadamer, Derrida and Ricoeur also explored the lingual aspect as such, via the human activity of textual interpretation, revealing its hermeneutic cycle, relationships between texts and engagement with others via texts (antecipating the social).

In the antecipatory direction, we find Chomsky interested in social, external "E-language"; in showing this less interest than the internal I-language, was he tacitly acting out Dooyeweerd's distinction between antecipation and retrocipation? Habermas is one who ardently studied the role of the social aspect in lingual functioning, and the role of lingual in social functioning, in his Theory of Communicative Action. He tended, however, to conflate the two. He was also interested in norms that guide lingual functioning retrocipatorily, beyond the functionalist (formative) norms of mere achievement, including juridical-pistic norms of truth, sincerity and appropriateness, and aesthetic-pistic norms of dramaturgy. Arguably, Habermas had a broader aspectual view than most.

Though the information systems / technology field is interdisciplinary, Lee [2004] and Basden [2010] argue the centrality of the lingual aspect ("information"), but that it takes account of its neighbouring aspects, the formative in its manifestation as technology, the social as its fulfilment, and the economic as a common 
application (business and management). Recently, the latter has extended to include the aesthetic application in "hedonic" use [van der Heijden 2004].

This (incomplete) picture of the field may be taken as an exemplar of how aspectual analysis of discourses in a field may be carried out. We see the discourses gradually opening up the "coherence of meaning" of the lingual with other aspects.

\subsection{The Social Aspect}

The social aspect's kernel, Dooyeweerd expressed as "social intercourse": 'we', togetherness, agreement, company, community, etc. Roles, relationships, groups, organisations, etc. are meaningful in the social aspect. The organisational side of business along with individuals' roles, is part of its social aspect.

Dooyeweerd's discussion of the kernel of the social aspect is surprisingly meagre [1955,II, 141,227-8], though he does have a lengthy discussion of social categories and institutions [NC,III, 565-624; Dooyeweerd, 1986]. His discussion of retrocipation to the lingual and formative aspects is limited to pointing out how social forms like lifting one's hat (a politeness of early 20th century Europe) are symbolic significations that are historically and culturally developed. Habermas' discussion of the dependency on the lingual shows greater depth, though with a tendency to conflate them. Luhmann recognised the irreducibility of the social to the lingual.

The social aspect introduces the possibility of social structures, raising the question of how this affects and is affected by individual agency (the macro-micro relationship). Giddens' Structuration Theory has therefore proven useful and may be affirmed, critiqued and enriched using Dooyeweerd, but that has yet to be worked out [Basden 2018, 297-9].

Many in the social sciences quietly presume that all post-social functioning can be reduced to (explained in terms of) the social, but Dooyeweerd argues that economics, aesthetics, juridicality, attitudes and faith cannot be reduced thereto but are antecipated by the social, as in social exchange antecipating exchange of goods, and social agreement antecipating aesthetic harmony.

\subsection{The Economic Aspect}

The kernel of the economic aspect is neither money, capital, productive labour nor competition, but frugality the management of resources treated as limited - which, of course, lies at the core of business activity. Value and resource are concepts not explainable without the economic aspect. Anything can be treated as resource, by targeting other aspects: minerals (physical), vegetables (biotic), ideas (analytical), friends (social), etc. Most of Dooyeweerd's discussion [NC,II, 66-7,122-7,344-5,360-2] is devoted to economy of thought, logic, language, aesthetics and law.

This helps clarify ideas. Production adds a strong formative aspect. Currency is not primarily economic but lingual expression of quantitative transduction of value, hence problems with crypto-currencies.

Dooyeweerd does not much discuss 'the economy', though he does criticise much economic thought of his time for being dominated by a mechanistic view (physical aspect) [p.344]. Marx's error was to absolutize the economic aspect [NC,II,293]. That of capitalism is dysfunction in the ethical aspect [NC,III,595-6]. Treating economic growth as essential not only deifies the economic aspect, requiring sacrifice of what is valuable in other aspects, but it treats as absolute what is merely a biotic analogy. It may be the field of conservation and the new economics of Prosperity without Growth [Jackson 2009] that most closely express Dooyeweerd's understanding of the kernel norm of this aspect.

Dooyeweerd's view might become increasingly useful in a planet-limited future, with his acknowledgement of antecipation of juridical, ethical and faith aspects in the very heart of economics rather than a bolt-on; see Gunton et al. [2017].

\subsection{The Aesthetic Aspect}

The kernel of the aesthetic aspect, Dooyeweerd argued, is harmony (as in a symphony): playing together to generate something more than their sum. Style, fun, humour, art, leisure and sport are all meaningful in the aesthetic aspect. The aesthetic aspect is key to business coherence and holistic views. 
Dooyeweerd's discussion is fragmented [NC,II, 66-7,128,139,345-8] and concerned mainly with antecipations and retrocipations, such as to the economic, in that superfluity (economic dysfunction) undermines good aesthetics. The aesthetic aspect's creativity depends strongly on the formative. The beauty in logic, engineering, language, etc. are aesthetic functioning targeting the analytical, formative and lingual aspects, while in "The great artists are shapers of style" [p.345], we see the formative aspect targeting the aesthetic. Seerveld [2001] and others argue that the kernel is allusivity, delight, etc. and the debate continues. Some believe there are two aspects there, but there might be an intuitive link between them.

\subsection{The juridical aspect and fields}

The juridical aspect concerns 'due', appropriateness or rightness. Topics meaningful therein include justice, rights, responsibility, proportionality, retribution (reward, punishment), impartiality, legality and their corresponding dysfunctions - all of which are important in business. Dooyeweerd argues that true justice depends on the aesthetic aspect (taking all into account) to achieve impartiality.

As Professor of Jurisprudence with practical experience of working in politics, Dooyeweerd developed an extensive philosophy of law, politics and the state. Chaplin [2011] develops this for contemporary contexts, to yield the beginnings of a conceptual framework that counters what he saw as a prevailing "narrow focus on institutions as opposed to behavior or processes" [p.161]. He discusses the identity of the state as being qualified by the juridical aspect and founded on the formative-historical aspect, along with important supportive roles played by other aspects. Because of its juridical qualification, the state's primary norm is justice, more than power, infrastructure-provision or defence. Chaplin believes Dooyeweerd's idea of legal pluralism is "original and fruitful" [p.210], though he questions Dooyeweerd's discussion of the tension between absolutism and democracy.

What we here call the target aspect helps to distinguish the different institutional spheres of sovereignty in society, for example family, church, economy/industry etc. (meaningful in the social, pistic and economic aspects respectively). This helps us judge (justly) between claims made by various spheres and can inform discussions of issues like worker participation in industry.

\subsection{The Ethical Aspect}

The ethical aspect goes beyond justice, rights and law to goodness and self-giving love. Mercy and forgiveness make sense only with the ethical aspect. Meaningful in this aspect are attitudes like generosity, self-sacrifice, vulnerability (hence trust), and their negatives, meanness, self-interest and self-protection. Buber's I-Thou relationship is somewhat self-giving.

In business the ethical aspect is exhibited, for example, in the attitude that pervades it: collaborative or competitive. The field called 'ethics' is often juridical in nature (e.g. privacy) or conflated with religion. Dooyeweerd [1955,II, 140-63] discusses the long confusion around legality and morality, including by Kant, Rousseau, Buber, Aristotle, the Scholastics, Heymans, Aalders, Brunner and others. Nietzschean or Foucauldian notions of power misunderstand the ethical aspect [c.f. Basden 2020, 160].

\subsection{The Pistic Aspect}

The pistic aspect concerns beliefs, commitments, aspirations, reliance (assumptions, presuppositions), motivations and ultimate meaningfulness. These range from those in religion and ideology to the tiny assumptions in everyday life such as sitting on a chair without testing it. Courage and faithfulness (and cowardice and disloyalty) are pistic functioning. These are important in business vision, motivation and perseverance. Dooyeweerd argued that the pistic aspect opens us to the Divine.

Good pistic functioning depends on ethical self-giving. However, the pistic aspect has no antecipations. Dooyeweerd [NC,II, 298-334] discusses the role of faith in the process of opening up all the aspects via their sciences. He argues cogently that pistic functioning is fundamental and inescapable in the working of all sciences, contrary to popular assumption that faith plays no role. Even the development and choice of paradigm [Kuhn 1962; Masterman 1970] is pistic functioning.

In $[N C, I]$ he charts the course of two basic commitments at work in academia over the past 500 years, which he calls the Science Ideal and the Ideal of Personality, the former trying to mathematise or rationalise everything 
into objective, deterministic laws like those in the natural sciences, and the latter emphasising freedom and human subjectivity. Dooyeweerd places himself within a third alternative, which he called "Christian", which views that dichotomy as false and always tending to deify specific aspects, whereas he wanted to value all aspects equally and welcome diversity in coherence and freedom within lawfulness. Such fundamental positions arise from what he calls "ground-motives," which constitute a "spiritual driving force that acts as the absolutely central mainspring of human society" in that it "not only places an indelible stamp on the culture, science, and social structure of a given period but determines profoundly one's whole world view" [Dooyeweerd 1979, 9].

\subsection{Aspects Meaningful to Fields}

With these insights we can clarify what each field finds primarily meaningful, as core and other aspects. Each field studies, and is guided by, the laws of its core aspect(s) rather than others. Table 2 gives a list of fields, with core aspect(s) in column 2 and other aspects in column 3, which are the main ones foundationally depended on, antecipated or analogies. "Target" indicates that a target aspect is also likely to be involved, which can be any aspect. For example, optometry is primarily concerned with the psychical aspect but requires considerable knowledge from the physical, spatial and biotic aspects to support the diagnosts of eye conditions and the prescription of glasses.

Nevertheless, it must be borne in mind that most aspects are meaningful in some ways in every field, so the clarification below is a simplification.

Table 2: Some fields and the aspects meaningful to them

Copyright (c) The Dooyeweerd Pages 2021, used with permission.

$\begin{array}{lll}\text { Field } & \text { Core aspect(s) } & \text { Other aspects } \\ \text { Arithmetic } & \text { Quantitative } & \\ \text { Algebra } & \text { Quantitative } & \text { Lingual (symbols) } \\ \text { Statistics } & \text { Quantitative } & \\ \text { Bayesian Statistics } & \text { Quantitative } & \text { Pistic } \\ \text { Trigonometry } & \text { Quantitative } & \text { Spatial } \\ \text { Differential calculus } & \text { Quantitative } & \text { Kinematic } \\ \text { Geometry } & \text { Spatial } & \\ \text { Topology } & \text { Spatial } & \text { Kinematic } \\ \text { Geography } & \text { Spatial } & \text { Social } \\ \text { Phoronomy } & \text { Kinematic } & \\ \text { Mechanics } & \text { Kinematic } & \text { (Physical) } \\ \text { Animation } & \text { Kinematic } & \text { Psychical } \\ \text { Physics } & \text { Physical } & \\ \text { Astronomy } & \text { Physical } & \text { Spatial } \\ \text { Chemistry } & \text { Physical } & \\ \text { Materials Science } & \text { Physical } & \text { Spatial } \\ \text { Geology } & \text { Physical } & \text { Spatial (Biotic) } \\ \text { Biochemistry } & \text { Physical } & \text { Biotic } \\ \text { Physiology } & \text { Biotic } & \text { Physical } \\ \text { Biology } & \text { Biotic } & \\ \text { Anatomy } & \text { Biotic } & \text { Analytical, Physical } \\ \text { Surgery } & \text { Biotic } & \text { Formative } \\ \text { Health } & \text { Biotic } & \text { Social } \\ \text { Psychology (Behaviourist) } & \text { Psychical } & \\ \text { Neural studies } & \text { Psychical } & \text { Biotic } \\ \text { Optometry } & \text { Psychical } & \text { Physical, Spatial, Biotic } \\ \text { Psychoanalysis } & \text { Psychical } & \text { Lingual } \\ \text { Mental Health } & \text { Psychical } & \text { Social } \\ \text { Cognitive Psychology } & \text { Analytical } & \text { Psychical } \\ & & \end{array}$




\begin{tabular}{|c|c|c|}
\hline Field & Core aspect(s) & Other aspects \\
\hline Logic & Analytical & \\
\hline Analysis & Analytical & Formative \\
\hline Decision Sciences & Formative & Analytical \\
\hline Engineering & Formative & \\
\hline Technology & Formative & Target \\
\hline History & Formative & Social \\
\hline Computer Science & Formative & Analytical \\
\hline Architecture & Formative & Physical, Spatial, Aesthetic \\
\hline Linguistics, Semiotics & Lingual & \\
\hline Information Science & Lingual & Analytical \\
\hline Hermeneutics & Lingual & Analytical, Social \\
\hline Sociolinguistics & Lingual & Social \\
\hline Languages & Lingual & Social \\
\hline Literature & Lingual & Social, Aesthetic \\
\hline Media & Lingual & Social, Psychical \\
\hline Information Technology & Lingual & Formative \\
\hline Information Systems & Lingual & Social, Formative \\
\hline Education & Lingual & Social, Psychical \\
\hline Sociology & Social & \\
\hline Organisational Studies & Social & Formative \\
\hline Socioeconomics & Social & Economic \\
\hline Economics & Economic & \\
\hline Finance & Economic & Quantitative \\
\hline Banking & Economic & Quantitative, Social \\
\hline Business and Management & Economic & Social, Formative \\
\hline Conservation & Economic & Biotic, Juridical \\
\hline Art & Aesthetic & Formative \\
\hline Painting & Aesthetic & Formative, Psychical, Spatial \\
\hline Music & Aesthetic & Formative, Psychical, Kinematic \\
\hline Drama & Aesthetic & Formative, Psychical \\
\hline Sport & Aesthetic & Formative, Biotic \\
\hline Leisure & Aesthetic & Psychical \\
\hline Law & Juridical & \\
\hline Security & Juridical & Formative \\
\hline Politics & Juridical & Social, Pistic \\
\hline Emancipatory studies & Juridical & Ethical, Social \\
\hline $\begin{array}{l}\text { 'Ethics' } \\
\text { ("business ethics") }\end{array}$ & Juridical & Ethical \\
\hline Ethics & Ethical & \\
\hline Attitude Studies & Ethical & \\
\hline Theology & Pistic & \\
\hline Standpoint Studies & Pistic & \\
\hline Anthropology & Pistic & Social \\
\hline Continental Philosophy & Pistic & Analytical \\
\hline Analytic Philosophy & Analytical & Pistic \\
\hline
\end{tabular}

It is largely a field's main aspects that determine which research methods are appropriate, as will be discussed in a forthcoming article. This table does not represent the richness of each of the fields, because other aspects are important in each, but it does attempt to suggest which are the most important aspects, so that fields may 
understand why other fields are important. In the discussion that follows we open up some of these more nuanced inter-field relationships.

Basden [2010] suggested that most fields focus on one core aspect and the nearest neighbours, as depicted in Figure 2a. While that is a useful approximation, the above table shows a more a more complex involvement of aspects, sometimes more distant from their core ones, as in music, depicted in Figure $2 b$. Figure $2 a$ shows interaspect dependency, of the core aspect on its immediate neighbours, and emerging from the core aspect. Figure $2 \mathrm{~b}$ shows not only that (good aesthetic functioning of music depends on good functioning in the economic and juridical aspects, not included in the table above, and shown by thinner lines) but also other inter-aspect relationships, in that music is a dynamic and highly sensory artform. It may be argued whether the relationship to the formative aspect is in fact inter-aspect dependency.

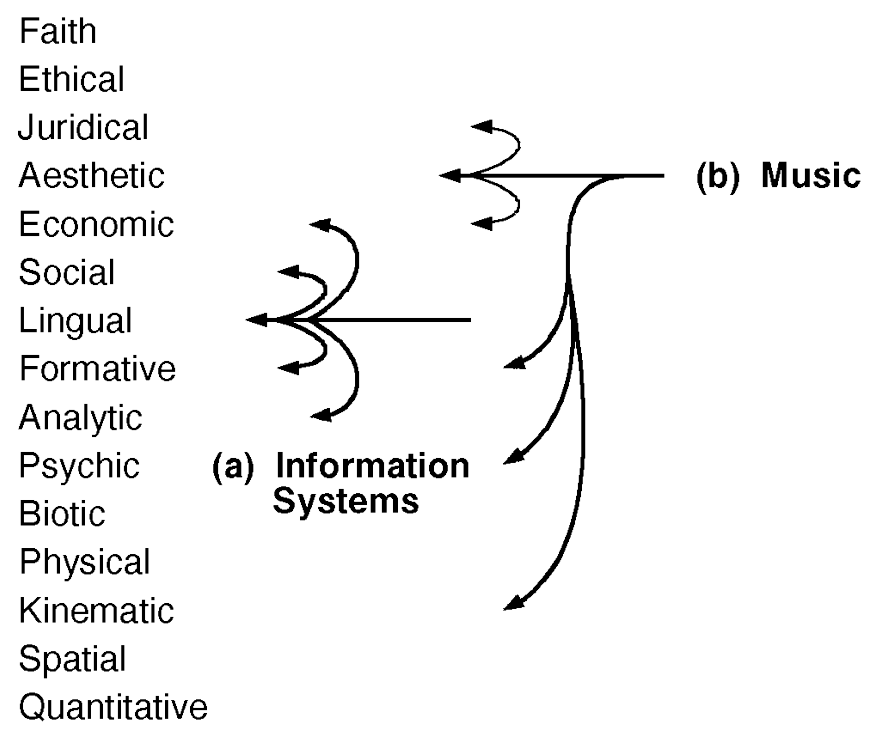

Figure 2: Fields and their aspects. (a) Information systems as depicted in Basden [2010]. (b) Music, as in the table above

\section{Discussion}

The above analysis has shown how we may understand the potential relationships among fields. Each field focuses its study and action on what its core aspect makes meaningful, often together with a few other aspects. This suggests that other fields that have those aspects as their core are likely to be referenced more.

The beauty of this approach is that it is common across all fields, from the mathematical, natural, psychological, design, social and societal sciences. This offers an integrative understanding, which can be highly useful in achieving full integrative interdisciplinarity [Strijbos \& Basden 2006], and the mutual respect between fields that we seek. Three examples of how this works out must suffice, one of disrespect, one of respect and one of interdisciplinary working.

At the start of the paper we mentioned Carr's [2003] provocative paper "IT doesn't matter." His seeming arrogance may be rooted in two errors, both of which may be usefully understood via aspects. (1) He treats IT as a mere technology to be used, thus emphasising its formative founding aspect rather than its main, lingual, aspect, so misunderstands it. (2) He treats the economic aspect as of ultimate importance, completely overlooking the contribution made by the lingual aspect. Such "deification" [NC,II, 335] is harmful in arousing an unhelpful reaction and undermines one's own predictions.

This is the whole point of Dooyeweerd's insistence on "coherence of meaning," in that all aspects must work together in harmony. Both business and IT have equally-important parts to play in this. While it is valid for Carr to treat IT as serving the needs of business, is it not equally valid to treat business as serving the needs of technology by provisioning its research and development? Is it not even more valid to see them both as serving wider aims of the entire diversity of coherence of meaning, which includes climate and environmental responsibility? 
We may contrast Carr's opinion piece with Davis' [1989] research that lead to his classic Technology Acceptance Model (TAM). Funded by IBM, Davis' research was designed to assess users' acceptance of IT tools in their workplaces. His final model is relatively simple: Degree of acceptance or use of a technology depends on Behavioral Intention to Use the technology and/or Attitude to Technology, which depend on Perceived Usefulness (PU) and Perceived Ease of Use (PEOU). Though making the same error as Carr, in emphasising IT's formative aspect, and restricting his context to that of business (economic aspect), he shows respect for other aspects and their fields in two ways.

One is that, although his main concern lies in the formative aspect, in being about both technology and its use to achieve tasks, he is explicit about other aspects (though by different names). He recognises the importance of the psychical aspect, emphasising the word "Perceived" in relation to ease of use and usefulness, and using psychological theories to build a model of individuals' attitude to, and thus acceptance of, IT. Though he assumed an organisational (social aspect) context, he recognises the need to research use in other settings. He also suggests the roles of beliefs and attitudes (pistic, ethical aspects) should be studied in future research.

The second is that TAM makes space for all other aspects at least potentially, in that PU and PEOU are to be measured by choosing "external variables." These are chosen by analysts who employ TAM to express what PEOU and PU mean in their contexts. In his context of 1980s organisational use, Davis used concepts like Understandable, Quality of work, Mental effort, which are meaningful in other aspects (lingual, ethical, psychical respectively). This may be seen as tacit recognition that a variety of aspects might be meaningful, different ones in different ways in different contexts, which lends TAM an element of modesty that may partly explain its later widespread success. Fields centred on those aspects can supply the variables needed.

Yousafzai et al. [2007] collected over 80 external variables used with TAM over the next decade, and Basden [2018, 200-202] shows their distribution throughout almost every aspect, for example, Age, Gender (biotic), Perceived enjoyment (aesthetic), Voluntariness (ethical). Whatever context, we can expect all aspects to feature in some way, so it is no surprise that revisions of TAM arose that incorporated some of these explicitly.

The research that led to them might, however, have been speeded up had the importance of all aspects been more explicitly recognised from the start. In such ways, careful consideration of Dooyeweerd's aspects by researchers, and of inter-aspect relationships, can make research even more fruitful than it currently is.

This is especially so in interdisciplinary research. Research in cognitive systems, for example, involves a plethora of concerns, as is evident in the collection of chapters in Nefti \& Gray [2010]. Being a collection of the work of many researchers cooperating in this field, their book ranges over embodiment, environment, robots, architecture, computation, metrics, imitation, cooperation, strategy, and much more. How may we understand this seemingly fragmented interdisciplinarity? That is the question posed in its final chapter [Basden \& Kutar 2010], which employs aspects to understand what each chapter is about and to plot an overall picture.

Most papers have two aspects that are most important to their topic. Chapter 13, for example, discusses the building of a cognitive model of investor behaviour, in order to enrich our knowledge of how investors make decisions, and may also be employed in agent-based artificial intelligence. So the paper links the economic aspect that makes financial investment meaningful with the analytical aspect of clarifying and conceptualising the various cognitive factors involved, such as risk, goals, demographics, personality and motivation. Chapter 4 likewise applies the analytical aspect to an application domain, which is the movements of humanoid robotic toys, in which the kinematic is the primary aspect. In contrast with both, Chapter 2 discusses how "morphological computation" about body parts and materials can help in controlling sensorimotor interaction of robots with the world around. This chapter is not about application of cognitive systems but about the physico-biotic and psychical aspects of how to build them. The overall picture is shown in Figure 3, in which each chapter, designated by its number, is shown as a relationship between aspects. 


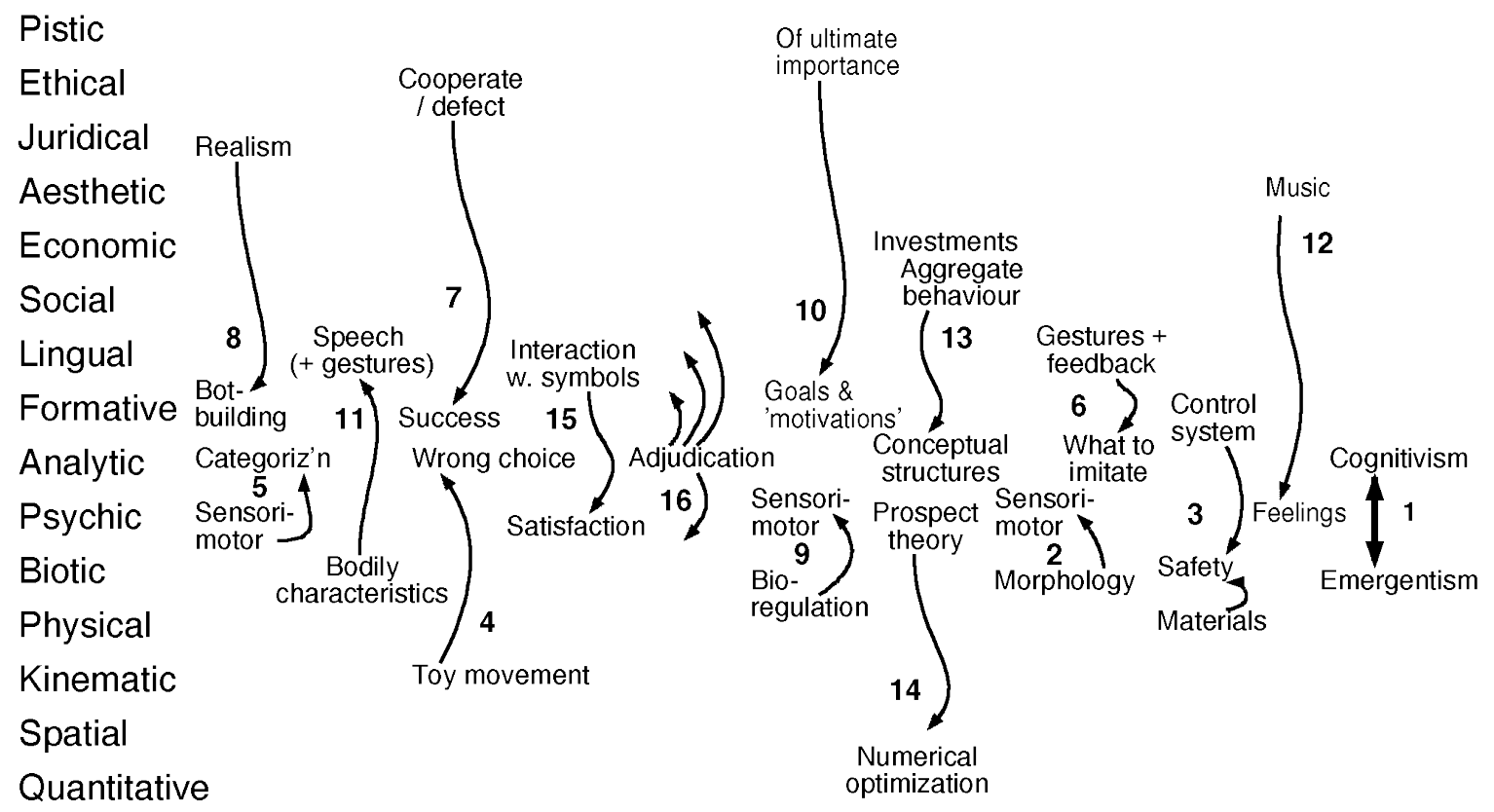

Figure 3: Aspectual profiles of cognitive modelling papers. Based on Figure 1 of Basden \& Kutar [2010].

What this picture shows is that (a) nearly every aspect is meaningful somewhere, which reveals the diversity of interests in cognitive systems, (b) there is nevertheless a coherent core to cognitive systems, meaningful in the psychical, analytic and formative aspects. Such an aspectual analysis can give an overall picture of interdisciplinarity as it occurs in real projects. It may perhaps be deepened by examining what kind of interaspect relationship(s) each arrow signifies, whether it is dependency in either direction, analogy or targeting (especially in application).

\section{Conclusion}

Understanding research fields in the way discussed above fosters attitudes of humility and service rather than arrogance or isolation, by turning our attention to equally-valid and equally-important aspects that are the domain of other fiels. Dooyeweerd allows us to address that head-on, not only by a general philosophical affirmation of meaningfulness but also by offering, in his suite of aspects, a conceptual tool with which to analyse in what ways things are meaningful. This avoids the sterile reactions of each party proclaiming their importance irrespective of others, and allows gentler, wiser consideration of the multiple importances of each. This approach might reduce tensions and fruitlessness invoked by arrogance and defensiveness between fields, and increase and encourage mutual respect and working together. It might help to enrich interdisciplinary working, from mere collaboration towards fuller integrated interdisciplinarity.

It now behoves researchers and thinkers in all fields to critically explore this approach further. Further research may be carried out to (a) explore more deeply the usefulness of aspect identification as in Table 2 and Figure 2 above; (b) assess to what extent fields whose core aspect is a secondary aspect of another field are referenced more; (c) survey inter-field arrogance and humility using aspects, as in the examples of Carr and Davis above; (d) enhance existing models in any field, but especially business, by augmenting them with factors that are meaningful in their missing aspects, as suggested for TAM above; (e) gain deeper experience of how to depict the diversity and coherence of interdisciplinary fields using aspects, as in Figure 3 above, perhaps distinguishing more clearly the various kinds of inter-aspect relationship. Then we can (f) evaluate to what extent this approach really is helpful across all fields, as has been suggested here - a topic for the philosophy of science.

\section{References}

Basden A. 2010. On Using Spheres of Meaning to Define and Dignify the IS Discipline. International Journal of Information Management, 30, 13-20.

Basden A. 2018. Foundations of Information Systems: Research and Practice. Routledge, London, UK.

Basden A. 2020. Foundations and Practice of Research: Adventures with Dooyeweerd's Philosophy. Routledge.

Bunge M. 1979. Treatise on basic philosophy, Vol. 4: Ontology 2: A world of systems. Boston: Reidal. 
Carr N. 2003. IT doesn't matter. Harvard Business Review, (May), 1-10.

Chaplin J. 2011. Herman Dooyeweerd: Christian Philosopher of the State and Civil Society. University of Notre Dame Press, Notre Dame, IN, USA.

Clouser R. 2005. The Myth of Religious Neutrality; An Essay on the Hidden Role of Religious Belief in Theories. University of Notre Dame Press, Notre Dame, Indiana, USA.

Davis FD. 1989. Perceived usefulness, perceived ease of use, and user acceptance of information technology. MIS Quarterly, 13(3), 319-340.

Dooyeweerd H. 1955. A New Critique of Theoretical Thought, Vol. I-IV, Paideia Press (1975 edition), Jordan Station, Ontario.

Dooyeweerd H, 1979. Roots of Western culture; Pagan, Secular and Christian options. Wedge Publishing Company, Toronto, Canada.

Geertsema HG. 2002. Which causality? Whose explanation? Philosophia Reformata, 67(2), 173-185.

Gibson JJ. 1979. The Ecological Approach to Visual Perception. Boston: Houghton Mifflin.

Gunton RM, van Asperen E, Basden A, Bookless D, Araya Y, Hanson DR, Goddard MA, Otieno G, Jones GO. 2017. Beyond ecosystem services: valuing the invaluable. Trends in Ecology and Evolution April 2017, 32 (4), 249-257.

Hartmann N. 1952. The New Ways of Ontology Chicago University Press.

Jackson, T. 2009. Prosperity Without Growth: Economics for a Finite Planet. London: Earthscan.

Klee V. 1960. Unsolved problems in intuitive geometry. University of Washington, Seattle, WA, USA.

Kuhn TS. 1962/1996. The Structure of Scientific Revolutions, Univ. Chicago Press.

Lee AS. 2004. Thinking about social theory and philosophy in information systems. pp. 1-26 in John Mingers, Leslie Willcocks. (Eds.). Social theory and philosophy for information systems. John Wiley \& Sons, Chichester, UK.

Maslow A. 1943. A theory of human motivation. Psychological Review, 50, 370-396.

Masterman M. 1970. The nature of a paradigm. pp. 59-89 in I. Lakatos, A. Musgrave (eds.), Criticism and the Growth of Knowledge, Cambridge University Press.

Maturana H, Varela F. 1980. Autopoiesis and Cognition: The Realization of the Living. Reidel.

NC. See Dooyeweerd H. 1955.

Nefti S, Gray JO (eds.). 2010. Advances in Cognitive Systems. London, U.K.: The Institution of Engineering and Technology. Polanyi M, Prosch H. 1975. Meaning. University of Chicago Press, Chicago, USA.

Seerveld C. 2001. Christian aesthetic bread for the world. Philosophia Reformata, 66(2), 155-76.

Strauss DFM. 2009. Philosophy, Discipline of the Disciplines. Paideia Press, Grand Rapids, Michigan, USA.

Strijbos S, Basden A, eds. 2006. In Search of an Integrative Vision of Technology: Interdisciplinary Studies in Information Systems. Springer, New York, USA.

Urbanska K, Huet S, Gumond S. 2018. Does increased interdisciplinary contact among hard and social scientists help or hinder interdisciplinary research? PLOS ONE, 14(9), e0221907.

van der Heijden H. 2004. User acceptance of hedonic information systems. MIS Quarterly 28(4), 694-704.

Winch P. 1958. The Idea of a Social Science and its Relation to Philosophy, London: Routledge and Kegan Paul.

Yousafzai SY, Foxall GR, Pallister JG. 2007. Technology acceptance: a meta-analysis of the TAM: Part 1. Journal of Modelling in Management, 2(3), 251-280. 